\title{
Hemodynamic and anti-inflammatory effects of early esmolol use in hyperkinetic septic shock: a pilot study
}

Bruno Levy ${ }^{1,2,3,7^{*}}$ D , Caroline Fritz ${ }^{1,2,3}$, Caroline Piona ${ }^{1,2,3}$, Kevin Duarte ${ }^{4}$, Andrea Morelli4,5, Philippe Guerci, Antoine Kimmoun ${ }^{1,2,3}$ and Nicolas Girerd ${ }^{4}$

\begin{abstract}
Background: Several studies have shown that heart rate control with selective beta-1 blockers in septic shock is safe. In these trials, esmolol was administered $24 \mathrm{~h}$ after onset of septic shock in patients who remained tachycardic. While an earlier use of beta-blockers might be beneficial, such use remains challenging due to the difficulty in distinguishing between compensatory and non-compensatory tachycardia. Therefore, the Esmosepsis study was designed to study the effects of esmolol aimed at reducing the heart rate by $20 \%$ after the initial resuscitation process in hyperkinetic septic shock patients on (1) cardiac index and (2) systemic and regional hemodynamics as well as inflammatory patterns.
\end{abstract}

Methods: Nine consecutive stabilized tachycardic hyperkinetic septic shock patients treated with norepinephrine for a minimum of $6 \mathrm{~h}$ were included. Esmolol was infused during $6 \mathrm{~h}$ in order to decrease the heart rate by $20 \%$. The following data were recorded at hours $\mathrm{HO}$ (before esmolol administration), $\mathrm{H} 1-\mathrm{H} 6$ (esmolol administration) and $1 \mathrm{~h}$ after esmolol cessation (H7): systolic arterial pressure, diastolic arterial pressure, mean arterial pressure, central venous pressure, heart rate, PICCO transpulmonary thermodilution, sublingual and musculo-cutaneous microcirculation, indocyanine green clearance and echocardiographic parameters, diuresis, lactate, and arterial and venous blood gases.

Results: Esmolol was infused 9 (6.4-11.6) hours after norepinephrine introduction. Esmolol was ceased early in 3 out of 9 patients due to a marked increase in norepinephrine requirement associated with a picture of persistent cardiac failure at the lowest esmolol dose. For the global group, during esmolol infusion, norepinephrine infusion increased from $0.49(0.34-0.83)$ to $0.78(0.3-1.11) \mu \mathrm{g} / \mathrm{min} / \mathrm{kg}$. The use of esmolol was associated with a significant decrease in heart rate from $115(110-125)$ to 100 (92-103) beats/min and a decrease in cardiac index from 4.2 (3.1-4.4) to 2.9 $(2.5-3.7) \mathrm{l} / \mathrm{min} / \mathrm{m}^{-2}$. Indexed stroke volume remained unchanged. Cardiac function index and global ejection fraction also markedly decreased. Using echocardiography, systolic, diastolic as well as left and right ventricular function parameters worsened. After esmolol cessation, all parameters returned to baseline values. Lactate and microcirculatory parameters did not change while the majority of pro-inflammatory proteins decreased in all patients.

Conclusion: In the very early phase of septic shock, heart rate reduction using fast esmolol titration is associated with an increased risk of hypotension and decreased cardiac index despite maintained adequate tissue perfusion (NCT02068287).

\footnotetext{
${ }^{*}$ Correspondence: blevy5463@gmail.com

${ }^{1}$ Service de Médecine Intensive Et Réanimation Brabois, CHRU Nancy, Pôle Cardio-Médico-Chirurgical, 54511 Vandœuvre-lès-Nancy, France

Full list of author information is available at the end of the article
}

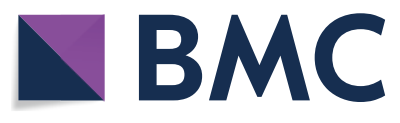

(c) The Author(s) 2021. Open Access This article is licensed under a Creative Commons Attribution 4.0 International License, which permits use, sharing, adaptation, distribution and reproduction in any medium or format, as long as you give appropriate credit to the original author(s) and the source, provide a link to the Creative Commons licence, and indicate if changes were made. The images or other third party material in this article are included in the article's Creative Commons licence, unless indicated otherwise in a credit line to the material. If material is not included in the article's Creative Commons licence and your intended use is not permitted by statutory regulation or exceeds the permitted use, you will need to obtain permission directly from the copyright holder. To view a copy of this licence, visit http://creativecommons.org/licenses/by/4.0/. The Creative Commons Public Domain Dedication waiver (http://creativeco mmons.org/publicdomain/zero/1.0/) applies to the data made available in this article, unless otherwise stated in a credit line to the data. 
Keywords: Septic shock, Inflammation, Norepinephrine, Beta-blockers

\section{Introduction}

The use of high-dose norepinephrine (NE) and concurrent tachycardia are associated with poor outcomes in septic shock (1). Despite the fact that the majority of the trials displayed beneficial results for selective and very short half-life beta 1-blocker use in patients with septic shock $(2,3)$, there is still a need for a large RCT (4). The majority of these trials used esmolol $24 \mathrm{~h}$ after onset of septic shock in patients who remained tachycardic (5, 6). It remains unknown whether early esmolol treatment might yield better results. (7). On the other hand, an early use of beta-blockers might be difficult due to the challenge in distinguishing between the compensatory or non-compensatory origin of tachycardia (8). Indeed, in the very early phase of septic shock, the combinational effects of inflammatory mediators, fluid loading and increasing afterload with NE may worsen myocardial contractility. In this condition, tachycardia is a crucial compensatory response. On the other hand, the so-called dysautonomic tachycardia is associated with a concomitant reduction in diastolic time, in ventricular filling and, ultimately, in cardiac index. In this instance, the use of selective beta- 1 blockers may prove beneficial. This latter point is highlighted by rodent studies using beta-blockers that show either a maintenance or an increase in cardiac output despite the decrease in heart rate. In human septic shock treated with beta-blockers, depending on the studies, cardiac index either decreased or remained stable but with good tolerance with regard to tissue oxygenation parameters. Therefore, the Esmosepsis study was designed to study the effects of esmolol aimed at reducing the heart rate by $20 \%$ after the initial resuscitation process in hyperkinetic septic shock on (1) cardiac index and (2) systemic and regional hemodynamics as well as inflammatory patterns.

\section{Materials and methods}

\section{Study design and oversight}

The University Hospital Center in Nancy (France) designed and sponsored the trial. Trial administration, data management and statistical analysis were performed by the sponsor. The executive committee had unrestricted access to the data, and the authors analyzed the data and prepared the manuscript. This single-center pilot phase 2 open-label study was conducted between December 2013 (first inclusion) and March 2017 (last follow-up) in two French Intensive Care Units (ICU) in Nancy France (NCT02068287, Esmolol Effects on Heart and Inflammation in Septic Shock (ESMOSEPSIS)). The study received the approval of the Nancy Hospital Institutional Review Board (Board (CPP 12.12.03, EudraCT: 2012-004532-32). Written informed consent was obtained from the patients or their closest relatives. The trial was overseen by an independent data safety monitoring board.

\section{Study population}

Patients with septic shock according to the 2012 criteria (9) were eligible if they were older than 18 years of age and fulfilled the following criteria: (1) inclusion as soon as possible after at least six hours of norepinephrine administration and fluid optimization using dynamic parameters; (2) a cardiac index higher than $3 \mathrm{l} / \mathrm{min} / \mathrm{m}^{2}$ and (3) a heart rate higher than 100 beats $/ \mathrm{min}$.

Exclusion criteria were shock of other origin, severe septic cardiomyopathy and history of severe asthma, patients without social assurance, and adult patients under legal protection.

\section{Study treatments and protocol}

Norepinephrine and esmolol doses are expressed in $\mu \mathrm{g} /$ $\mathrm{kg} / \mathrm{min}$. In instances of a decrease in MAP during esmolol infusion, norepinephrine doses were increased by $0.02 \mu \mathrm{g} / \mathrm{kg} / \mathrm{min}$ (or higher in emergency cases). The targeted MAP was $65-70 \mathrm{mmHg}$.

\section{Esmolol administration}

Esmolol (Brevibloc ${ }^{\mathrm{R}}$, Baxter, Saint-Quentin-en-Yvelines, France) was initiated at $7.5 \mu \mathrm{g} / \mathrm{kg} / \mathrm{min}$ implemented in 5 -min increments until the effects on heart rate were reached. Treatment duration with esmolol was $6 \mathrm{~h}$ maximum. The maximum maintenance dose was $200 \mu \mathrm{g} /$ $\mathrm{kg} / \mathrm{min}$. If the goal of $20 \%$ heart rate reduction was not achieved with the maximum maintenance dose of $200 \mu \mathrm{g} /$ $\mathrm{kg} / \mathrm{min}$, the patient remained treated with this dose until the end of the $6 \mathrm{~h}$ and was evaluated as such. In cases of a greater than $20 \%$ decrease in cardiac index during esmolol infusion, its dosage was reduced by $25 \mu \mathrm{g} / \mathrm{kg} / \mathrm{min}$ until restoration of the cardiac index to the safety target. A hemodynamic evaluation was performed prior to each dose modification. If a preload dependency was identified, the patient underwent vascular filling using $250 \mathrm{ml}$ saline infused in $10 \mathrm{~min}$ until resolution. Fluid optimization was performed using passive leg raising and $\mathrm{PICCO}$ transpulmonary thermodilution and pulse contour analysis as previously described (10). 


\section{Monitoring}

Transpulmonary thermodilution and pulse contour analysis

All patients had an internal jugular vein catheter and a thermistor-tipped arterial catheter (PV2024 Pulsion Medical Systems, Munich, Germany) inserted in the femoral artery and connected to the PiCCO2 device. Three cold boluses were administered when performing transpulmonary thermodilution. This allowed measuring cardiac index (CI) (through transpulmonary thermodilution and pulse contour analysis), global end-diastolic volume and extravascular lung water (both through transpulmonary thermodilution). Global ejection fraction, index stroke volume and cardiac function index were calculated according to standard formulas.

\section{Sidestream dark field (SDF) methodology}

Microcirculation was assessed using a Sidestream Dark Field (SDF) imaging device (Microscan ${ }^{\circledR}$, MicroVision Medical, Amsterdam, Netherlands). An automated Vascular Analysis software (AVA 3.0 Software, MicroVision Medical, Amsterdam, Netherlands) was used for image analysis according to current guidelines (11). Five sublingual areas were focused for at least $>20 \mathrm{~s}$ at each measurement. The following parameters were collected: total and perfused vessel density (TVD, PVD), proportion of perfused vessels (PPV) and microvascular flow index (MFI).

Plasma disappearance rate of indocyanine green (ICG-PDR) The plasma disappearance rate of indocyanine green (ICG-PDR) was used as a dynamic test for the assessment of liver function and global hepatosplanchnic blood flow (12). The ICG-PDR was assessed with a noninvasive liver function monitoring system (LiMon, Pulsion Medical Systems, Munich, Germany). Each patient received an ICG finger clip connected to the liver function monitor. A dose of $0.25 \mathrm{mg} / \mathrm{kg}$ of ICG was injected through a central venous catheter.

\section{Near infrared spectroscopy (NIRS)}

Tissue oxygen saturation (StO2) was measured by a tissue spectrometer (InSpectra Model 325, Hutchinson Technology, Hutchinson, Minn.) through reflectance mode probes to measure scattering light reflected at a distance from where the light is transmitted into the tissue. The NIRS probe was placed on the skin of the thenar eminence and a sphygmomanometer cuff was wrapped around the arm over the brachial artery. After a 3-min NIRS signal stabilization period, arterial inflow was stopped by inflating the cuff to $50 \mathrm{mmHg}$ above the systolic arterial pressure. When $\mathrm{StO}_{2}$ was under $40 \%$, cuff pressure was released, and $\mathrm{StO}_{2}$ was recorded continuously for another 3 min period (reperfusion period). Baseline $\mathrm{StO}_{2}$ was recorded prior to the ischemic period, the lowest $\mathrm{StO}_{2}$ recorded at the end of the ischemic period, and the highest $\mathrm{StO}_{2}$ recorded during the reperfusion phase. The slope of the increase in StO2 obtained by the regression line of the first five $\mathrm{StO}_{2}$ values (14 s) during the reperfusion phase following the ischemic period $\left(\mathrm{StO}_{2}\right.$ resaturation slope, expressed in \% per second) as well as the difference between the maximum $\mathrm{StO}_{2}$ value during the hyperemic phase and the baseline $\mathrm{StO}_{2}\left(\mathrm{StO}_{2}\right.$ overshoot $)$ were calculated. The $\mathrm{StO}_{2}$ desaturation slope (expressed in \% over time) during the ischemic phase was also calculated.

\section{Echocardiography}

Echocardiography was performed by an experimented investigator using a Vivid E90 (GE Healthcare) in which the following parameters were recorded: velocity time integral (VTI), left ventricular ejection fraction (LVEF), tricuspid annular plane systolic excursion (TAPSE), transmitral $E / A$ ratio (E/A), $e^{\prime}$ velocity (average and absolute value of septal and lateral side) and systolic $\left(s^{\prime}\right)$ velocity of lateral tricuspid annulus by pulsed tissue Doppler.

\section{Olink $^{\circledR}$ Inflammation reagent kit}

Plasma samples were collected at $\mathrm{HO}$ and $\mathrm{H} 6$ and stored at the study sites at $-20{ }^{\circ} \mathrm{C}$, followed by storage at $-80{ }^{\circ} \mathrm{C}$ at the central laboratory. Olink ${ }^{\circledR}$ Inflammation is a reagent kit measuring 92 inflammation-related human protein biomarkers simultaneously. Measurement details can be found at https://www.olink.com/conte nt/uploads/2019/04/Olink-Infla mmation-Validation -Data-v3.0.pdf.

\section{Measured variables}

The following data were recorded at hours HO (before esmolol administration), $\mathrm{H} 1$ to $\mathrm{H} 6$ (esmolol administration) and $1 \mathrm{~h}$ after esmolol cessation (H7): systolic arterial pressure (SAP), diastolic arterial pressure (DAP), mean arterial pressure (MAP), central venous pressure, heart rate, PICCO transpulmonary thermodilution, NIRS, SDF, Limon and echocardiography parameters, diuresis, lactate, and arterial and venous blood gases. Indexed oxygen delivery (DO2i) and indexed oxygen consumption $\left(\mathrm{VO}_{2} \mathrm{i}\right)$ were calculated using standard formulas.

\section{Outcomes}

Primary Outcome:

Since the decrease in heart rate directly influences cardiac index, the change in CI was selected as the primary outcome variable during the entire administration period and one hour after esmolol cessation.

Secondary outcome measures: 
1. Effects on vasopressor requirement (amount of norepinephrine infused in microgram $/ \mathrm{kg}$ ) during esmolol administration: recording of each change in vasopressor dosage to maintain a mean arterial pressure at $70 \mathrm{mmHg}$ during the entire esmolol administration period ( $\mathrm{HO}$ to $\mathrm{H} 6$ ) and one hour after esmolol cessation (H7).

2. Microcirculatory and regional circulation effects of esmolol in septic shock patients. NIRS (near-infrared spectroscopy), SDF (Sidestream Dark Field imaging) / Limon were used to assess microcirculatory and regional circulation effects.

3. Changes in the cytokine pattern induced by esmolol administration in septic shock patients before administration of esmolol ( $\mathrm{HO})$ and $6 \mathrm{~h}$ after introduction of esmolol (H6).

4. Description of cardiac function during esmolol administration in septic shock patients. Echocardiography was used to assess ventricular function.

\section{Statistical analysis}

Sample Size Calculation. The primary endpoint of this pilot study was the change in cardiac index between $\mathrm{HO}$ and $\mathrm{H} 6$ in response to esmolol administration. A sample size of 25 patients would be required to detect a 0.6 SD change in cardiac index with a power of $80 \%$ and a 2 -tailed significance level of $5 \%$. Based on 31 patients in septic shock with a similar profile and hospitalized in our department, such a difference corresponds to a variation of $0.6 \mathrm{~L} / \mathrm{min} / \mathrm{m}^{2}$ in cardiac index, $2.5 \%$ in ejection fraction and $0.5 \mu \mathrm{g} / \mathrm{kg} / \mathrm{min}$ in norepinephrine dosage.

Continuous variables are described as median (interquartile range) and categorical variables as frequencies (percentages). Values at $\mathrm{H0}$ and at $\mathrm{H} 6$ as well as values at $\mathrm{H} 0$ and $\mathrm{H} 7$ were compared using the Wilcoxon signedrank test for all continuous variables. For the three patients who prematurely discontinued the study treatment, values at $\mathrm{H} 6$ were replaced with the last value prior to treatment cessation and values at $\mathrm{H} 7$ were replaced with the first value after treatment cessation.

All analyses were performed using R statistical software (version 3.6.1, R Foundation for Statistical Computing, Vienna, Austria). The 2-tailed significance level was set at $p<0.05$ with no adjustment for multiple comparisons.

\section{Results (Tables 1, 2, 3, 4 and 5, Fig. 1 and Additional file 1)}

The study was terminated prior to enrollment completion due to a shift in ICU recruitment leading to a low inclusion rate. Nine consecutive stabilized tachycardic hyperkinetic septic shock patients treated with norepinephrine for a minimum of $6 \mathrm{~h}$ were included (Table 1 ).
Esmolol was infused 9 (6.4-11.6) hours after norepinephrine introduction. Esmolol was ceased early in 3 out of 9 patients due to a marked increase in norepinephrine requirement associated with a picture of persistent cardiac failure at the lowest esmolol dose (Table 1: patients 7-9).

\section{Primary outcome (Fig. 1 and Table 2)}

The use of esmolol was associated with a significant decrease in heart rate from $115(110-125)$ to 100 (92$103)$ beats $/ \mathrm{min}(p=0.004)$, and a significant decrease in cardiac index from $4.2(3.1-4.4)$ to $2.9(2.5-3.7) \mathrm{l} / \mathrm{min} /$ $\mathrm{m}^{-2}(p=0.004)$ without any change in either stroke volume or left ventricular end diastolic volume. Double product, a surrogate of myocardial oxygen consumption, also markedly decreased during esmolol infusion $(p=0.008)$. There was a trend towards a decrease in echocardiographic left ventricular ejection fraction $(p=0.074)$.

\section{Secondary outcome}

For the global group, during esmolol infusion, the hourly amount of administered, norepinephrine significantly increased (Fig. 1; Table 2) $(p<0.05) . \mathrm{ScVO}_{2}$ and venousarterial $\mathrm{PCO}_{2}$ gap remained unchanged (Table 2). Cardiac function index and global ejection fraction also significantly decreased (Table 2). Using echocardiography, systolic, diastolic as well as left and right ventricular function parameters significantly worsened (Table 3 ). After esmolol cessation, all parameters returned to baseline values.

Oxygen delivery significantly decreased while oxygen consumption remained unchanged (Table 2)

Lactate (Table 4) and microcirculatory parameters (Table 5) did not change, while the majority of proinflammatory proteins decreased in all patients (Additional file 1, additional table).

\section{Post-hoc analysis}

Diuresis significantly decreased during esmolol infusion $(p=0.016)$.

\section{Subgroup analysis after excluding patients who did not complete the study (Additional file 1; additional table)}

The evolution of heart rate, cardiac index, stroke, systemic vascular resistance volume, cardiac power index, cardiac function index, global ejection fraction, arterial-venous gases, lactate, SDF, ICG clearance and NIRS parameters remained similar. The evolution of the following parameters became non-statistically significant with a p value near 0.06: diuresis, VTI and TAPSE. The 


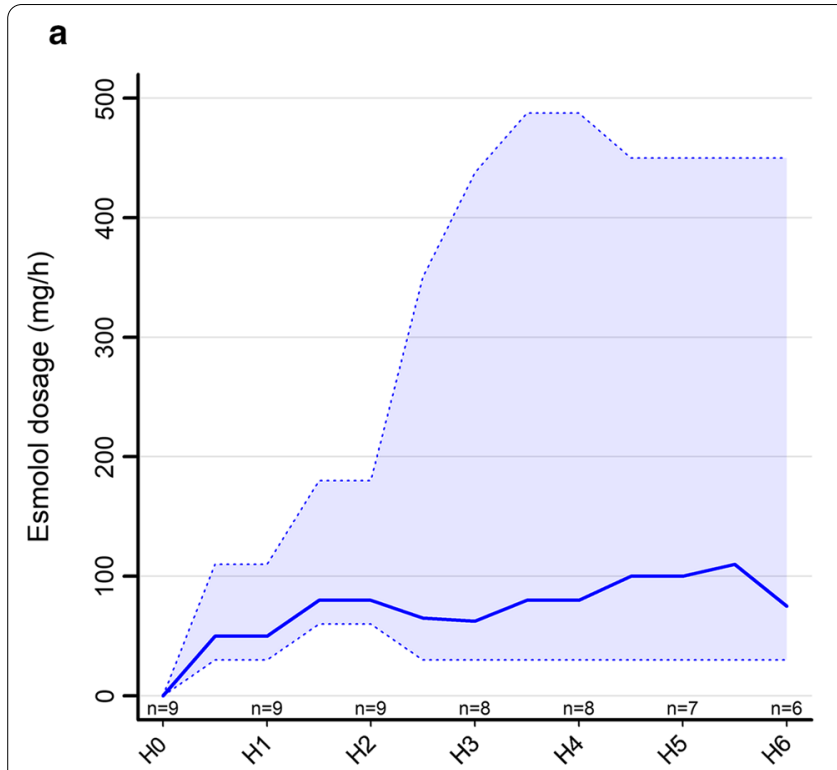

b

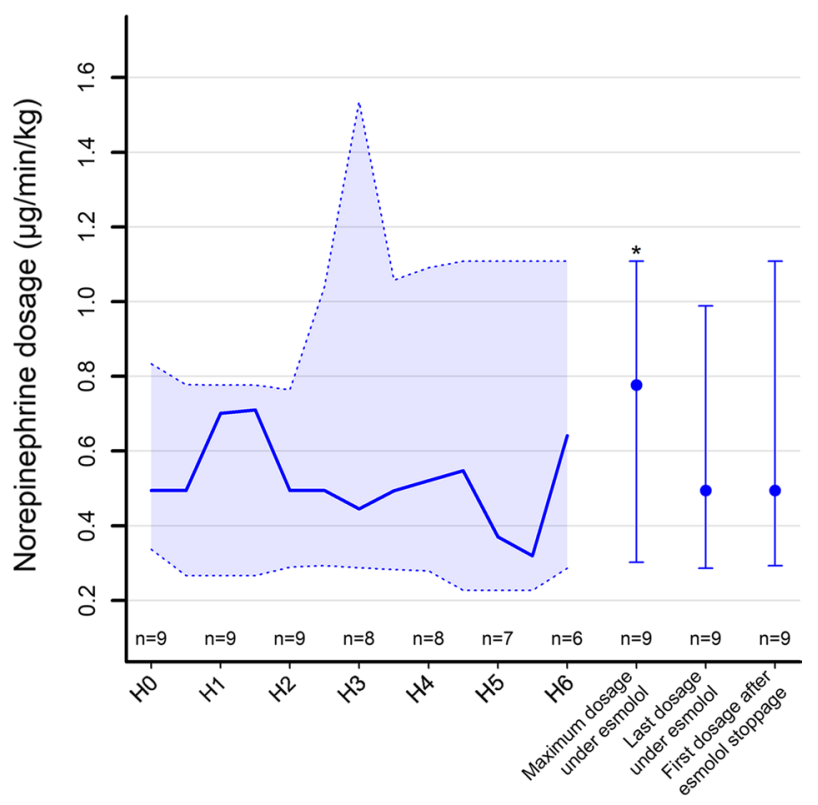

C

d
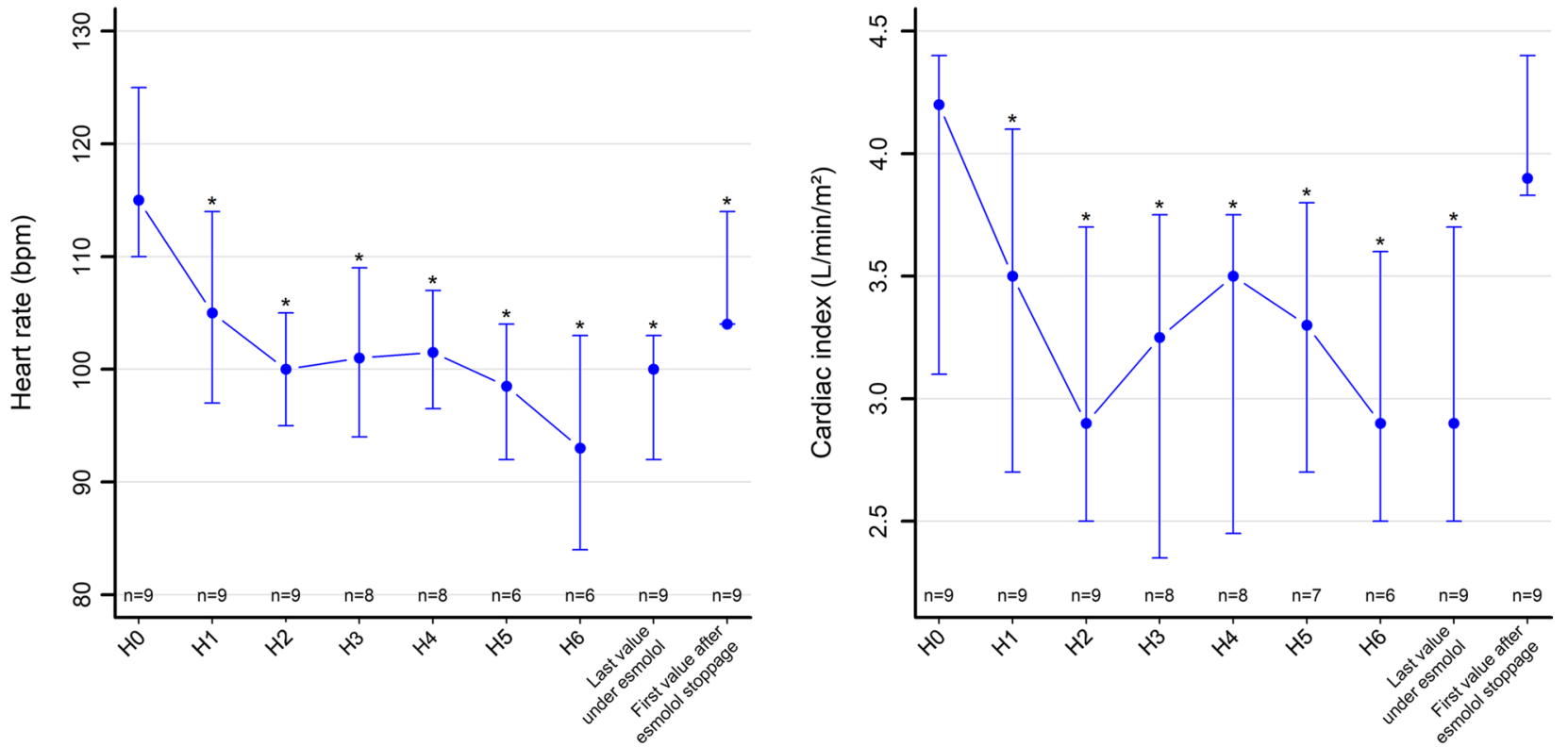

Fig. 1 a, b Solid lines are median values while the shaded areas bordered by dotted lines represent the upper and lower quartiles. c, $\mathbf{d}$ Points are median values, with the vertical bars indicating the interquartile range. The symbol $\left(^{*}\right)$ indicates a significant difference compared to $\mathrm{HO}$ by the Wilcoxon signed-rank test $(p<0.05)$. M1 = maximum value under esmolol, $\mathrm{M} 2$ = last value under esmolol, $\mathrm{M} 3=$ first value after esmolol cessation

evolution of the hourly amount of required norepinephrine changed from a significant difference $(p=0.027)$ to a non-significant change $(p=0.094)$. Similarly, echocardiographic LVEF changed from a tendency to decrease $(p=0.074)$ to a non-significant change $(p=0.44)$.

\section{Discussion}

The main results of the present study are that an early administration of esmolol in norepinephrine-treated hyperkinetic septic shock was associated with an increased risk of major hypotension and decreased cardiac index in one third of the patients. For the remaining 
Table 1 Patient characteristics

\begin{tabular}{|c|c|c|c|c|c|c|c|}
\hline Patient & Sex & Age & Sepsis etiology & SAPS II & SOFA & $\begin{array}{l}\text { Norepinephrine HO } \\
\mu \mathrm{g} / \mathrm{min} / \mathrm{kg}\end{array}$ & $\begin{array}{l}\text { Timing norepinephrine- } \\
\text { esmolol introduction } \\
\text { (hours) }\end{array}$ \\
\hline 1 & $F$ & 82 & Infectious pneumonia & 79 & 12 & 2.00 & 8 \\
\hline 2 & $\mathrm{H}$ & 58 & Candidemia & 61 & 14 & 0.57 & 9 \\
\hline 3 & $H$ & 54 & Colo-pericardial fistulae & 72 & 7 & 0.44 & 8 \\
\hline 4 & $\mathrm{~F}$ & 65 & Infectious pneumonia & 26 & 8 & 0.20 & 11 \\
\hline 5 & $\mathrm{~F}$ & 59 & Ascitis & 66 & 14 & 0.91 & 10 \\
\hline 6 & $\mathrm{H}$ & 71 & Soft skin & 139 & 16 & 0.66 & 12 \\
\hline 7 & $\mathrm{H}$ & 61 & Infectious pneumonia & 66 & 9 & 0,13 & 4 \\
\hline 8 & $F$ & 83 & Biliary tract infection & 73 & 14 & 0.83 & 5 \\
\hline 9 & $F$ & 24 & Peritonitis & 58 & 8 & 0.49 & 13 \\
\hline
\end{tabular}

SAPS // Simplified Acute Physiology II Score, SOFA Sequential Organ Failure Assessment, HO O hours (baseline)

Table 2 Global hemodynamic and transpulmonary thermodilution parameters. Comparison H0-H6

\begin{tabular}{|c|c|c|c|c|}
\hline & $\mathrm{HO}$ & $\mathrm{H} 6$ & $\Delta \mathrm{H} 0-\mathrm{H} 6(\mathrm{H} 6-\mathrm{H} 0)$ & $p$ value ${ }^{* *}$ \\
\hline Heart rate (bpm) & $115(110 ; 125)$ & $100(92 ; 103)$ & $-18(-25 ;-15)$ & 0.004 \\
\hline $\mathrm{SAP}(\mathrm{mmHg})$ & $110(102 ; 117)$ & $103(99 ; 104)$ & $-9(-14 ; 1)$ & 0.16 \\
\hline $\mathrm{DAP}(\mathrm{mmHg})$ & $54(47 ; 55)$ & $55(54 ; 59)$ & $4(0 ; 8)$ & 0.12 \\
\hline MAP $(\mathrm{mmHg})$ & $72(68 ; 72)$ & $72(67 ; 75)$ & $0(-3 ; 4)$ & 0.52 \\
\hline Double product (mm Hg.bpm) & $13,266(12,138 ; 15,065)$ & $9682(8736 ; 10,609)$ & $-2657(-3305 ;-2628)$ & 0.008 \\
\hline $\mathrm{Cl}\left(\mathrm{L} / \mathrm{min} / \mathrm{m}^{2}\right)$ & $4.2(3.1 ; 4.4)$ & $2.9(2.5 ; 3.7)$ & $-0.6(-1.2 ;-0.5)$ & 0.004 \\
\hline $\mathrm{SVi}\left(\mathrm{mL} / \mathrm{m}^{2}\right)$ & $29.8(27.3 ; 37.8)$ & $28.2(27.2 ; 36.5)$ & $-0.2(-5.2 ;-0.0)$ & 0.25 \\
\hline $\mathrm{CPI}\left(\mathrm{W} / \mathrm{m}^{2}\right.$ & $0.61(0.54 ; 0.70)$ & $0.48(0.40 ; 0.58)$ & $-0.10(-0.17 ;-0.06)$ & 0.008 \\
\hline SVRi (dyn s m² $\mathrm{cm}^{-5}$ ) & $1164(1143 ; 1412)$ & $1379(1333 ; 1876)$ & $190(139 ; 427)$ & 0.004 \\
\hline $\mathrm{CFI}(1 / \mathrm{min})$ & $6.1(4.8 ; 7.4)$ & $3.7(3.5 ; 4.8)$ & $-1.9(-2.6 ;-1.0)$ & 0.004 \\
\hline $\mathrm{EPLW}(\mathrm{mL} / \mathrm{kg})$ & $8(7 ; 12)$ & $9(8 ; 11)$ & $0(-1 ; 1)$ & 0.91 \\
\hline $\mathrm{CVP}(\mathrm{mmHg})$ & $8(5 ; 8)$ & $8(6 ; 12)$ & $1(0 ; 2)$ & 0.58 \\
\hline GEF (\%) & $20(17 ; 21)$ & $17(15 ; 19)$ & $-3(-3 ;-2)$ & 0.004 \\
\hline Diuresis (mL/h) & $100(50 ; 150)$ & $50(10 ; 70)$ & $-60(-90 ;-50)$ & 0.016 \\
\hline $\mathrm{SvcO}_{2}(\%)$ & $73.6(70.0 ; 87.0)$ & $75.3(71.0 ; 77.0)$ & $-3.5(-7.0 ; 3.5)$ & 0.47 \\
\hline $\mathrm{DO}_{2} \mathrm{i}\left(\mathrm{ml} / \mathrm{min} / \mathrm{m}^{-2}\right)$ & $444(333 ; 615)$ & $366(319 ; 437)$ & $-68(-98 ;-64)$ & 0.031 \\
\hline $\mathrm{VO}_{2} \mathrm{i}\left(\mathrm{ml} / \mathrm{min} / \mathrm{m}^{-2}\right)$ & $79(61 ; 119)$ & $93(72 ; 96)$ & $-6(-13 ; 16)$ & 0.84 \\
\hline Norepinephrine $(\mu \mathrm{g} / \mathrm{kg})$ & $29.7(20.2-50)$ & $38.1(18.1-66.5)$ & $10.4(5.7-25.5)$ & 0.027 \\
\hline
\end{tabular}

HO O hours (baseline), H6 $6 \mathrm{~h}, \mathrm{SAP}$ systolic arterial pressure, DAP diastolic arterial pressure, MAP mean arterial pressure, Double product SAP x HR, Cl cardiac index, $S V i$ indexed stroke volume, CPI cardiac power index, SVRi indexed systemic vascular resistances, CFI cardiac function index, EPLW extra pulmonary lung water, CVP central venous pressure, GEF global ejection fraction, $\mathrm{SvCO}_{2}$ central venous oxygen saturation, $\mathrm{DO}_{2} i$ indexed oxygen delivery, $\mathrm{VO}_{2} i$ indexed oxygen consumption, norepinephrine $=$ hourly amount of norepinephrine

patients, esmolol was associated with moderate hypotension necessitating an increase in norepinephrine and a depressed cardiac function without any effects on microcirculatory blood flow, lactate and $\mathrm{ScVO}_{2}$.

The main differences between the current study and the studies of Morelli et al. $(6,13)$ are the timing of esmolol infusion, the dose titration needed to achieve the predefined HR threshold which lasted $12 \mathrm{~h}$ in their study, with a first data collection point performed $24 \mathrm{~h}$ after esmolol initiation (thus $48 \mathrm{~h}$ after norepinephrine introduction versus $9 \mathrm{~h}$ in the present study), and a high use of levosimendan ( $49.3 \%$ versus $0 \%$ in our study). In the present study, esmolol administration had to be discontinued in one third of our septic shock patients due to a likely uncovered septic cardiomyopathy (14). Nevertheless, in the remaining patients, since stroke volume remained unchanged, the decrease in CI was predominantly related to the negative chronotropic effect of esmolol rather than a profound decrease in contractility. It is likely that the increase in norepinephrine doses participated in the 
Table 3 Echocardiographic parameters. Comparison H0-H6

\begin{tabular}{|c|c|c|c|c|}
\hline & HO & $\mathrm{H} 6$ & $\begin{array}{l}\Delta \mathrm{H} 0-\mathrm{H} 6 \\
(\mathrm{H} 6-\mathrm{H} 0)\end{array}$ & $p$ value \\
\hline LVEF (\%) & $53(50 ; 55)$ & $45(30 ; 57)$ & $-8(-18 ; 2)$ & 0.074 \\
\hline LVEDV & $89(56 ; 114)$ & $100(44 ; 119)$ & $9(-21 ; 43)$ & 0.38 \\
\hline VTI (cm) & $17(15 ; 17)$ & $14(12 ; 16)$ & $-2(-3 ;-1)$ & 0.008 \\
\hline TDSa (cm/s) & $11.0(8.0 ; 13.0)$ & $9.0(7.0 ; 12.0)$ & $-1.0(-2.1 ; 0.0)$ & 0.031 \\
\hline Peak E wave velocity $(\mathrm{m} / \mathrm{s})$ & $0.90(0.70 ; 1.00)$ & $0.84(0.80 ; 1.00)$ & $0.00(-0.10 ; 0.12)$ & 0.95 \\
\hline Peak E'wave velocity $(\mathrm{m} / \mathrm{s})$ & $0.11(0.09 ; 0.12)$ & $0.09(0.08 ; 0.10)$ & $-0.01(-0.03 ;-0.01)$ & 0.023 \\
\hline Peak A wave velocity $(\mathrm{m} / \mathrm{s})$ & $0.77(0.68 ; 1.03)$ & $0.57(0.47 ; 0.75)$ & $-0.21(-0.27 ;-0.06)$ & 0.016 \\
\hline $\mathrm{E} / \mathrm{A}$ & $0.91(0.80 ; 1.33)$ & $1.52(0.97 ; 1.88)$ & $0.47(0.20 ; 0.62)$ & 0.031 \\
\hline$E / E^{\prime}$ & $7.6(6.5 ; 9.0)$ & $9.5(8.4 ; 12.3)$ & $2.6(1.0 ; 3.3)$ & 0.023 \\
\hline DTI S' (cm/s) & $9.0(7.2 ; 14.0)$ & $9.0(8.0 ; 11.0)$ & $-1.0(-3.0 ; 0.0)$ & 0.16 \\
\hline TAPSE (mm) & $17.5(16.0 ; 21.5)$ & $15.5(14.0 ; 16.5)$ & $-1.0(-4.0 ;-0.5)$ & 0.031 \\
\hline \multicolumn{5}{|c|}{$\begin{array}{l}\text { HO O hours (baseline), } H 66 \mathrm{~h}, L V E F \text { left ventricular ejection fraction, } L V E D V \text { left ventricular end-diastolic volume, VT/ velocity time integral, TDSa Tissue Doppler lateral } \\
\text { mitral annulus peak systolic velocity, E/A early ventricular filling velocity to late ventricular filling velocity, E/E' mitral early diastolic velocity-to-early diastolic mitral } \\
\text { annulus velocity, DTIS' derived tricuspid lateral annular systolic velocity S' wave, TAPSE tricuspid annular plane systolic excursion }\end{array}$} \\
\hline & $\mathrm{HO}$ & $\mathrm{H} 6$ & $\begin{array}{l}\Delta \mathrm{H} 0-\mathrm{H} 6 \\
(\mathrm{H} 6-\mathrm{H} 0)\end{array}$ & $p$ value \\
\hline $\mathrm{pH}$ & $7.34(7.30 ; 7.39)$ & $7.36(7.31 ; 7.40)$ & $0.01(-0.09 ; 0.02)$ & 1.00 \\
\hline $\mathrm{PaCO}_{2}(\mathrm{mmHg})$ & $34.4(32.0 ; 36.0)$ & $32.4(26.2 ; 36.0)$ & $-3.3(-6.0 ; 6.4)$ & 0.84 \\
\hline $\mathrm{PvCO}_{2}(\mathrm{mmHg})$ & $37.4(26.4 ; 42.0)$ & $39.0(36.5 ; 41.0)$ & $-0.9(-1.0 ; 2.9)$ & 1.00 \\
\hline Delta $\mathrm{PCO}_{2}(\mathrm{mmHg})$ & $6.0(4.0 ; 7.3)$ & $6.0(5.3 ; 10.0)$ & $4.0(-2.0 ; 6.3)$ & 0.31 \\
\hline $\mathrm{SaO}_{2}(\%)$ & $95.9(94.3 ; 98.0)$ & $96.9(94.2 ; 98.0)$ & $0.5(-0.7 ; 1.0)$ & 0.62 \\
\hline Lactate (mmol/L) & $2.2(1.5 ; 4.8)$ & $2.4(1.5 ; 4.5)$ & $-0.1(-0.3 ; 0.2)$ & 0.69 \\
\hline
\end{tabular}

$\mathrm{PaCO}_{2}$ normal arterial partial tension, $\mathrm{PvCO}_{2}$ mixed venous carbon dioxide tension, Delta $\mathrm{PCO}_{2} \mathrm{PvCO}_{2}-\mathrm{PaCO}_{2}, \mathrm{SaO}_{2}$ oxygen saturation

Table 5 SDF, ICG clearance and NIRS parameters. Comparison H0-H6

\begin{tabular}{|c|c|c|c|c|}
\hline & $\mathrm{HO}$ & $\mathrm{H} 6$ & $\begin{array}{l}\Delta \mathrm{H} 0-\mathrm{H} 6 \\
(\mathrm{H} 6-\mathrm{H} 0)\end{array}$ & $p$ value \\
\hline \multicolumn{5}{|l|}{ SDF } \\
\hline Total vessel density & $17.90(14.88 ; 18.53)$ & $16.98(14.48 ; 19.56)$ & $-0.29(-0.82 ; 1.41)$ & 1.00 \\
\hline Perfused vessel density & $13.66(11.34 ; 14.49)$ & $14.51(12.31 ; 15.91)$ & $1.00(-1.26 ; 2.28)$ & 0.69 \\
\hline Proportion of perfused vessel & $67.41(58.98 ; 75.55)$ & $73.37(66.26 ; 81.58)$ & $3.96(-1.92 ; 13.83)$ & 0.31 \\
\hline Microvascular flow index & $1.96(1.50 ; 2.44)$ & $1.66(1.33 ; 2.44)$ & $-0.08(-0.54 ; 0.00)$ & 0.38 \\
\hline \multicolumn{5}{|c|}{$\begin{array}{l}\text { Plasma disappearance rate of indocyanine } \\
\text { green }\end{array}$} \\
\hline Clearance rate (\%/min) & $10.8(4.5 ; 17.0)$ & $11.0(4.7 ; 15.0)$ & $0.2(0.2 ; 0.5)$ & 0.62 \\
\hline Retention rate at 15 min (\%) & $19.8(6.9 ; 50.0)$ & $19.0(17.0 ; 49.4)$ & $-0.6(-0.8 ; 6.1)$ & 0.81 \\
\hline \multicolumn{5}{|l|}{ Near-infrared spectroscopy } \\
\hline $\mathrm{StO}_{2}$ & $74(70 ; 85)$ & $74(72 ; 84)$ & $1(-6 ; 2)$ & 0.82 \\
\hline $\mathrm{StO}_{2}$ overshoot (\%) & $82(76 ; 94)$ & $84(80 ; 90)$ & $-2(-3 ; 2)$ & 0.84 \\
\hline $\mathrm{StO}_{2}$ desaturation slope (\%/min) & $-6.6(-7.2 ;-4.5)$ & $-6.9(-8.7 ;-6.4)$ & $-0.2(-4.2 ; 0.1)$ & 0.44 \\
\hline $\mathrm{StO}_{2}$ resaturation slope $(\% / \mathrm{s})$ & $1.1(0.8 ; 2.2)$ & $1.2(1.1 ; 1.7)$ & $-0.0(-0.2 ; 0.3)$ & 1.00 \\
\hline
\end{tabular}

SDF Sidestream dark field, $\mathrm{StO}_{2}$ tissue oxygen saturation 
increase in systemic vascular resistance index and concomitant decrease in cardiac index due to the resulting inhibition of the cardiac beta-1 receptors (15). Several important points should be discussed. First, in the present study, a fast esmolol titration was used in the early phase of septic shock. After reducing the heart rate, myocardial performance can differ significantly between patients depending on the relationship between their preload, ventricular filling and myocardial contractility status. The optimal combination of these components may therefore require a careful and slow titration and thus a longer time to safely achieve hemodynamic stability at a lower heart rate. Secondly, on the one hand, esmolol decreased cardiac index without increasing lactate levels or impairing microcirculatory parameters and appeared to be associated with certain anti-inflammatory effects. One the other hand, esmolol was associated with a decrease in diuresis and a marked cardiac impairment. Importantly, extravascular lung water did not increase suggesting adequate contractility, albeit reduced. This is in line with preserved SV and perfusion variables. This discrepancy might be explained (with the exception of patients 7-9) by sympathetic overstimulation leading to non-compensatory tachycardia and resulting, in turn, to an unnecessarily elevated cardiac index. Therefore, decreasing the latter was not accompanied by a decrease in tissue perfusion. This point is further strengthened by the observed decrease in oxygen delivery without any change in oxygen consumption arguing for an independent DO2/VO2 relationship. Finally, the very short half-life of esmolol in this indication allows a rapid reversibility of potential deleterious hemodynamics effects. Therefore, in a number of patients, elevated heart rate may be compensatory for decreased contractility rather than noncompensatory (sympathetic overstimulation), even in the later phases of septic shock (8).

The present study has several limitations. First, the study was terminated early due to a low enrolment rate. Second, patients were not randomized and therefore some of the observed effects could be due to spontaneous evolution although all of the parameters returned to baseline values after discontinuing esmolol treatment. Finally, $6 \mathrm{~h}$ is likely not sufficient to ascertain the consequences of non-hemodynamic effects of selective beta-1 blocking.

\section{Conclusion}

In the very early phase of septic shock, heart rate reduction using a fast titration of esmolol is associated with an increased risk of hypotension and decreased cardiac index despite maintained adequate tissue perfusion.

\section{Supplementary Information}

The online version contains supplementary material available at https://doi. org/10.1186/s13054-020-03445-w.

Additional file 1. $\mathrm{H} 0-\mathrm{H} 6$ comparison after excluding the three patients who discontinued esmolol prematurelyAdditional Table 6. Olink inflammation panel. $\mathrm{HO}-\mathrm{H} 6$ comparison.

\section{Acknowledgements}

Not applicable.

\section{Authors' contributions}

Data acquisition and analysis: KD. Data interpretation: all authors. Manuscript drafting and revision: all authors. The authors read and approved the final manuscript.

\section{Funding}

Institutional funding: INSERM and CHU Nancy.

Availability of supporting data and materials

All data generated or analyzed during this study are included in this published article. The data used to support the findings of this study are available from the corresponding author upon reasonable request.

\section{Ethics approval}

The study received the approval of the Nancy Hospital Institutional Review Board (CPP 12.12.03, EudraCT: 2012-004532-32).

\section{Consent for publication}

Not applicable.

\section{Competing interests}

The authors disclosed that they received support from Baxter and AMOMED (grant for research) and from INSERM (institutional support). BL received consulting fees from Amomed.

\section{Author details \\ ${ }^{1}$ Service de Médecine Intensive Et Réanimation Brabois, CHRU Nancy, Pôle Cardio-Médico-Chirurgical, 54511 Vandœuvre-lès-Nancy, France. ${ }^{2}$ INSERM U1116, Faculté de Médecine, 54511 Vandœuvre-lès-Nancy, France. ${ }^{3}$ Univer- sité de Lorraine, 54000 Nancy, France. ${ }^{4}$ INSERM CIC1433, Nancy University Hospital, 54000 Nancy, France. ${ }^{5}$ Department of Internal Clinical, Anesthesio- logical and Cardiovascular Sciences, University of Rome, La Sapienza, Rome, Italy. ${ }^{6}$ Department of Anesthesiology and Intensive Care Medicine, University Hospital of Nancy, 54511 Vandœuvre-lès-Nancy, France. ${ }^{7}$ Medical Intensive Care Unit, University Hospital of Nancy, Brabois, Rue du Morvan, 54500 Van- dœuvre-lès-Nancy, France.}

Received: 7 October 2020 Accepted: 17 December 2020

Published online: 07 January 2021

\section{References}

1. Domizi R, Calcinaro S, Harris S, et al. Relationship between norepinephrine dose, tachycardia and outcome in septic shock: a multicentre evaluation. J Crit Care. 2020;57:185-90.

2. Lee YR, Seth MS, Soney D, et al. Benefits of beta-blockade in sepsis and septic shock: a systematic review. Clin Drug Investig. 2019;39:429-40.

3. Sanfilippo F, Santonocito C, Morelli A, et al. Beta-blocker use in severe sepsis and septic shock: a systematic review. Curr Med Res Opin. 2015;31:1817-25

4. Unger M, Morelli A, Singer M, et al. Landiolol in patients with septic shock resident in an intensive care unit (LANDI-SEP): study protocol for a randomized controlled trial. Trials. 2018;19:637.

5. van Loon LM, van der Hoeven JG, Lemson J. Hemodynamic response to beta-blockers in severe sepsis and septic shock: a review of current literature. J Crit Care. 2019;50:138-43. 
6. Morelli A, Ertmer C, Westphal M, et al. Effect of heart rate control with esmolol on hemodynamic and clinical outcomes in patients with septic shock: a randomized clinical trial. JAMA. 2013;310:1683-91.

7. De Backer D, Annane D. Beta-blockers in septic shock to optimize hemodynamics? We are not sure. Intensive Care Med. 2016:42:1613-4.

8. Morelli A, Romano SM, Sanfilippo F, et al. Systolic-dicrotic notch pressure difference can identify patients with septic shock at risk of cardiovascular decompensation in case of heart rate reduction. Br J Anaesth. 2020:125:1018-24.

9. Dellinger RP, Levy MM, Rhodes A, et al. Surviving Sepsis Campaign: international guidelines for management of severe sepsis and septic shock, 2012. Intensive Care Med. 2013;39:165-228.

10. Monnet X, Marik P, Teboul JL. Passive leg raising for predicting fluid responsiveness: a systematic review and meta-analysis. Intensive Care Med. 2016;42:1935-47.

11. De Backer D, Ospina-Tascon G, Salgado D, et al. Monitoring the microcirculation in the critically ill patient: current methods and future approaches. Intensive Care Med. 2010;36:1813-25.

12. Sakka SG, Koeck H, Meier-Hellmann A. Measurement of indocyanine green plasma disappearance rate by two different dosages. Intensive Care Med. 2004;30:506-9.
13. Morelli A, Donati A, Ertmer $\mathrm{C}$, et al. Microvascular effects of heart rate control with esmolol in patients with septic shock: a pilot study. Crit Care Med. 2013:41:2162-8.

14. Martin L, Derwall M, Al Zoubi S, et al. The septic heart: current understanding of molecular mechanisms and clinical implications. Chest. 2019;155:427-37.

15. Levy B, Buzon J, Kimmoun A. Inotropes and vasopressors use in cardiogenic shock: when, which and how much? Curr Opin Crit Care. 2019;25:384-90.

16. Ince $\mathrm{C}$. Hemodynamic coherence and the rationale for monitoring the microcirculation. Crit Care. 2015;19(Suppl 3):S8

\section{Publisher's Note}

Springer Nature remains neutral with regard to jurisdictional claims in published maps and institutional affiliations.
Ready to submit your research? Choose BMC and benefit from:

- fast, convenient online submission

- thorough peer review by experienced researchers in your field

- rapid publication on acceptance

- support for research data, including large and complex data types

- gold Open Access which fosters wider collaboration and increased citations

- maximum visibility for your research: over $100 \mathrm{M}$ website views per year

At $\mathrm{BMC}$, research is always in progress.

Learn more biomedcentral.com/submissions 